\title{
The Pragmatic Functions of the Discourse Marker Bas in Jordanian Spoken Arabic: Evidence from a Corpus
}

\author{
Rafat Al Rousan \\ Department of Translation, \\ Yarmouk University, Jordan \\ Ahmad Al Harahsheh \\ Department of Translation, \\ Yarmouk University, Jordan

\section{Fadia Huwari} \\ Department of Translation, \\ Yarmouk University, Jordan
}

Doi: 10.36941/jesr-2020-0012

\begin{abstract}
This study investigates the pragmatic functions of the discourse marker bas (Lit. But) in Jordanian Spoken Arabic. To this end, a corpus of 24 dyadic conversations, consisting of 93313 words were obtained from natural conversations of native speakers of Jordanian Arabic (males and females). 1113 instances of bas were identified in the data. This study is based on Fraser's (2006) grammatical-pragmatic framework. Qualitative methods were employed to answer the question of the study. The analysis was based on the pragmatic functions introduced by Brinton (1996) and Fraser (2006). The data analysis reveals that the DM bas serves the following pragmatic functions in JSA: initiating a topic, signaling topic change, closing a turn, ending a conversation, indicating speaker's hesitancy, mitigating Face Threatening Acts, making a correction, attracting hearer's attention, expressing restrictions and conditions, showing disbelief and indicating a question, providing interpretation, showing contrast, expressing regret, showing agreement, indicating emphasis, and finally filling in gaps in an interaction. Finally, this study suggests that DMs in Arabic play a vital role in people's daily communication; therefore, they should not be neglected by linguists.
\end{abstract}

Keywords: pragmatic functions, discourse markers, bas, Jordanian spoken Arabic

\section{Introduction}

Discourse markers (Henceforth DMs) are lexical items used in both speaking and writing to 'signpost' discourse. They are usually used to facilitate the production of a coherent conversation and, more specifically, to make speakers' intentions clearer. They also help participants to manage their interactions. DMs are linguistic elements that are predominantly used in oral conversations to relate units of discourse to each other (Fraser, 1990; Lenk, 1998; Louwerse \& Mitchell, 2003; Schiffrin, 1987). For instance, Louwerse and Mitchell (2003) have found 10 times more DMs in spoken than written 
discourse, and twice as many in informal than formal discourses. Scholars have claimed that DMs are grammatically optional and semantically empty, but they are pragmatically multifunctional (Brinton, 1996). DMs greatly contribute to the coherence of discourse as they connect units of discourse together. They can be either local, relating immediately adjacent units of talk to each other (Schiffrin, 1987), or global, signaling "relationships between segments that occur further apart in the discourse, or relationships with extra-conversational contexts" (Lenk, 1998, p. 256). Moreover, they facilitate interpretation and communication.

The study of DMs has been ongoing since the 1970s. Since then, it has drawn the attention of scholars around the world (Aijmer, 2002; Fraser, 2006; Lenk, 1998; Louwerse \& Mitchell, 2003; Müller, 2005; Schiffrin, 1987; Schorup, 1986, among others). However, it is still a field of research that requires further investigation, especially the pragmatic and interpersonal importance of DMs (Qainbo, 2016). Arabic is replete with DMs. However, little attention has been paid to them, particularly in spoken Arabic. JSA is a variety of Standard Arabic spoken all over Jordan.

The aim of this study is to investigate the pragmatic functions of the discourse marker bas, (Lit. but), in Jordanian Spoken Arabic (JSA). It attempts to answer the following question: What are the pragmatic functions of the discourse marker bas in Jordanian Spoken Arabic?

\section{Background}

\subsection{Definition of DMs}

In spite of being widely studied, scholars have not agreed upon a specific definition for DMs. They have assigned different names to them. For example, they have been labeled as discourse particles (Aijmer, 2002; Schorup, 1986), discourse operators (Redeker, 1991), pragmatic markers (Anderson, 2001; Fraser, 1996), pragmatic connectives (Louwerse \& Mitchell, 2003), discourse markers (Fraser, 2006; Müller, 2005; Lenk, 1998, Schiffrin, 1987), discourse formatives (Fraser, 1990), etc. The term discourse marker (DM) will be used in this study because it is the most common of all and the easiest to understand.

Scholars have also given numerous definitions for DMs. For example, Schiffrin $(1987$, p. 31) defines DMs as "sequentially dependent elements which bracket units of talk that signal relationships between immediately adjacent units of talk, and which have thus a coherence building function on a local coherence level." DMs are also defined as "a class of expressions, each of which signals how the speaker intends the basic message that follows to relate to the prior discourse" (Fraser, 1990, p. 387). Fraser (1999) characterizes DMs as conjunctions, adverbs and prepositional phrases used in a text to relate sentences or clauses together. Lenk (1998, p. 246) points out that the "term discourse marker refers only to expressions in spoken discourse that are used pragmatically, with a structuring and organizational function." Louwerse and Mitchell (2003) view DMs as cohesive links that establish coherence in discourse and facilitate communication and interpretation. Moreover, Hellerman and Vergun (2007) point out that DMs are words and phrases functioning within the linguistic system to maintain relations between grammatical constituents or topics in discourse. Taking the aforementioned definitions into consideration, DMs, in this study, will be considered as linguistic expressions that establish coherent discourse relations and serve textual and pragmatic functions.

\subsection{Features of DMs}

There has been some kind of agreement among linguists on the features of DMs. One of the most important defining features of DMs is that DMs occur utterance initially because they often introduce an upcoming utterance (Aijmer, 2002; Fraser, 1990; Lenk, 1998; Redeker, 1991; Schiffrin, 1987). This does not mean that they do not come medially or finally in discourse (Fraser, 1993; Lenk, 1998; Müller, 2005). Secondly, they occur with higher frequency in oral discourse than in written discourse (Brinton, 1996; Lenk, 1998; Schiffrin, 1987). Thirdly, the use of DMs is optional (Brinton, 1996; Lenk, 
1998; Muller, 2005; Schiffrin, 1987) since an utterance would stand as grammatical and meaningful without their presence. Schiffrin (1987, p. 31) states that "although markers often precede sentences, [...] they are independent of sentential structure. Removal of a marker from its sentence initial position, in other words, leaves the sentence structure intact."

Discourse markers enjoy a number of characteristics on almost all levels of language. Phonologically, DMs are often short and reduced forms of lexical items, and they form a distinct tone unit (Brinton, 1996). Lexically, they derive from lexical words and phrases such as verbs, adverbs, adjectives, prepositions, and modal words (Schourup, 1999; Yang, 2011). Syntactically, DMs are not obligatory; they are often separated or loosely attached to the beginning of an utterance; therefore, they are not part of the syntactic structure of a sentence (Fraser, 1990; Schourup, 1999). On a semantic level, DMs originate from lexical expressions having clear propositional meanings, which become ambiguous or propositionally empty when used as a DM (Brinton, 1996; Lenk, 1998). They do not add any truth value to the propositional content of the utterance in which they are used. In sociolinguistics, DMs are associated with informality and more typical of women's speech (Brinton, 1996). Finally, DMs are pragmatically multifunctional as they work on both the local and the global levels (Fraser, 1990; Lenk, 1998; Schiffrin, 1987; Schourup, 1999).

\subsection{Pragmatic Functions of DMs}

Previous studies have shown that DMs are used in conversations to serve a number of pragmatic functions, which are dependent on the context in which DMs occur (Brinton, 1996; Fraser, 1999; Redeker, 1991; Schiffrin, 1987). For example. Brinton (1996, p. 35) states that DMs 'are not pragmatically optional or superfluous: but they serve a variety of pragmatic functions' (p. 35). Firstly, DMs greatly contribute to the coherence of spoken discourse (Lenk, 1998; Schiffrin, 1987) since they connect a current turn and a previously mentioned one in discourse. According to Fraser (1999), DMs "signal a relationship between the interpretation of the segment they introduce, S2, and the prior segment, Si". Secondly, they connect adjacent and non-adjacent utterances and signal relationships between discourse turns (Lenk, 1998; Schiffrin, 1987; Schourup, 1999). They also help the addressee understand the meaning communicated by the speaker's utterance. Furthermore, DMs may be used to indicate the boundaries of discourse, its beginning and ending. Aijmer (2002) and Schiffrin (1987) mention that DMs can be either local or global. Local DMs indicate intersentential relationships, such as highlighting the propositional meaning of sentences, marking transitions between sentences. On the other hand, global DMs signal relationships between larger discourse units, such as introducing new topics, playing a role in turn-taking, marking the opening or closing of a conversation, etc. In addition, the functions of DMs are either textual or interpersonal (Brinton, 1996). The former includes initiating discourse, claiming the attention of the hearer, closing discourse, serving as filler or a turn holder, indicating a topic shift, signaling old or new information, repairing discourse, and marking sequential dependence. The interpersonal functions include the following: expressing attitudes, confirming shared assumptions, expressing understanding, requesting confirmation, expressing politeness, and expressing a response to a preceding discourse.

\section{Theoretical Framework}

This study is based on Fraser's (2006) grammatical-pragmatic framework. It is one of the three common approaches used in the study of DMs. In his approach, Fraser focuses on what DMs are and on what their grammatical status is. DMs, according to Fraser (1999, 2006, 2009), do not add to the semantic meaning of the sentence, but rather to the procedural meaning. They help the addressee interpret the utterance in which the DM is used. Fraser (2009) argues that DMs have the following typical features: (1) they are free morphemes; (2) they are proposition-initial; (3) they signal a specific message either about or in addition to the basic message; and (4) they are classified as pragmatic markers by virtue of their semantic /pragmatic functions (Fraser 2006). Fraser (1999, p. 936) classifies 
a DM as only a linguistic expression that "(i) has a core meaning which can be enriched by the context; and (ii) signals the relationship that the speaker intends between the utterance the DM introduces and the foregoing utterance (rather than only illuminating the relationship...)". Additionally, Fraser (2006, p. 196-197) classifies DMs according to the type of relationship these markers signal (e.g., "topic change markers", "contrastive markers", "elaborative markers", "inferential markers", and "temporal markers".

\section{Review of Literature}

The earliest mentioning of DMs goes back to the early 1970 by Lakoff, who investigated the use of well and why in different interactions. Then, they were mentioned by Labov and Fanshel (1977) who report that participants use DMs (e.g., well) to connect elements of oral discourse. Following their steps, Levinson (1983) points out that in most languages there are linguistic expressions (e.g., therefore, but, well, anyway, still, etc.) that signal relationships between preceding and following discourse. After that, Schiffrin (1987), introduces what seems to be the most influential investigations of DMs. She studies different kinds of DMs such as particles (oh, well), conjunctions (and, but, so, or), time deictic expressions (now, then), and lexicalized clauses (I mean). Schiffrin (1987) argues that DMs serve significant functions contributing to the coherence of discourse by relating what is being said to what has been already said. Fraser (1990, 1999, 2006, 2009), who approaches DMs from a grammatical-pragmatic perspective, claims that DMs do not have propositional value, but they convey various kinds of pragmatic meanings. Even though, Fraser and Schiffrin do not agree on the role played by the DMs, they both agree on the role played by the context in defining the meaning of DMs. He introduces two main types of context-based DMs: DMs that relate messages (contrastive, elaborative, and inferential) and DMs that relate topics. He indicates that there is similarity between DMs across languages. Like Fraser, Blackmore (1987) claims that DMs have no representational meaning; however, they have procedural meaning. She also claims that DMs have various pragmatic functions, such as allowing the derivation of a contextual implication (e.g., so, therefore, also, too), supporting a given assumption (e.g., moreover, after all, etc.), contradicting an existing assumption (e.g., however, but, etc.), and specifying the role of an utterance in discourse (e.g., anyway, finally, etc.). Brinton (1996) also argues that DMs have interpersonal functions by which they affect sharing, understanding and/or intimacy between participants (e.g. confirming shared assumptions, checking and/or expressing understanding, requesting confirmation, or saving face. Wang (2011), who studies the pragmatic functions of the Japanese DM ano and the Mandarin Chinese DM nage in interactional discourse, finds out that they serve multiple discourse-pragmatic functions based on the context in which they were used, including introducing a new referent/topic, mitigating various Face Threatening Acts, and, indicating the speaker's hesitancy in sharing certain personal information.

Many studies of DMs in different languages have discussed the pragmatic functions of DMs. Based on the relevance approach, Chen (2002) conducts a contrastive pragmatic analysis of DMs English and Chinese. He reveals how DMs influence the strength of utterance proposition. Ma (2003) mentions that in spite of some differences, DMs in English and Chinese perform common pragmatic functions in discourse. Müller's (2005) analyses in detail the frequencies and functions of four DMs (so, well, you know, and like) as used by Americans and Germans. Müller classifies the functions of the four DMs at two levels: textual and interactional. She finds out that the DMs so, you know and well serve a number of textual and interpersonal levels. However, like serves textual level only. Americans students were found to use so, you know and like more than German students. Well was used with the same frequency by both groups.

A number of studies have been conducted on the pragmatic functions of DMs is an Arab context. For example, Alazzawie (2015), who investigates the DM Ya:di "OK" in Iarqi spoken Arabic, finds out that this DM fulfills a number of pragmatic functions and textual functions. Al Rousan (2015) examines the use and functions of the DM mas nafsak "with yourself" in the online conversations of young Saudi people. His study shows that maS nafsak serves 12 different pragmatic 
functions. Studying the DM Inzeen (OK) in the Gulf Spoken Arabic, Abdeljawad and Radwan (2016) point out that Inzeen serve the following pragmatic functions: Agreement marker, tag marker, threat marker, cohesive marker, and topic management marker.

In a Jordanian context, Al-Harahsheh and Kanakri (2013) examine the pragmatic functions of the DM tayyib "Ok" and its cognate tab. Their findings reveal that these two DMs convey a number of pragmatic functions, some of which are: connecting discourse elements, signaling the end of discourse, filling a gap, mitigating an utterance, etc. Kanakri and Al-Harahsheh (2013) also study the functions of the DM ?a:di "normal" in JSA. It was reported that this DM was particularly used to mitigate the effect of a statement, save one's face, expressing agreement and disagreement, and showing indifference, etc.

\section{Methods}

\subsection{Data Collection}

The data of this study were extracted from a corpus of 24 dyadic conversations in JSA, 30 minutes each; these conversations were mixed-sex and single-sex recorded and transliterated by the researchers. All the participants were native speakers of Jordanian Arabic. They were all university students, and their age ranges from 18-26 years old. The corpus of the study consisted of (93313 words); the occurrences of bas in the data were (1113), about (1.19\%) of the data. Ghawwas software, which was developed for Arabic corpus concordance, was used in this study. It is an open source system for Arabic corpora processing. It provides frequency list of single word search, concordance, collocation, and lexical pattern search. The examples were selected, classified, transliterated, and translated. This study employs qualitative methods to answer its questions.

\subsection{Data Analysis}

The analysis of the data involved the identification and the description of the pragmatic function of the DM bas. It was based on the pragmatic functions introduced by Brinton (1996) and Fraser (2006). The data collected were transcribed by the researchers (all of them are native speakers of JSA). The DMs were then analyzed based on the context in which they occurred. In this study, the turn (exchange structure) is the basic unit of analysis; each unit contains a proposition. The analysis was done manually. Identifying the functions of bas was a tedious job since an individual DM sometimes serves multiple functions in a given context, and that some of them may overlap Brinton's (1996), Fraser's (1999), and Qianbo's (2016).Tallying was very difficult to use in this study because the functions of bas overlap to some extent, and sometimes they even look the same.

\section{Results and Discussion}

Based on the data, the pragmatic functions of bas were identified and classified. Sixteen main pragmatic functions were identified in the data. In what follows, these functions are presented and explained through illustrative examples. The examples are transliterated, and their English translations are given in square brackets. Due to word limitations, only one example on each category is discussed.

\subsection{Initiating a Topic}

Successful communication is a process whereby information is continuously exchanged between parties of a conversation. The speaker and the listener usually make sure that new information is always being introduced to keep the conversation smooth and going. Of course, the speaker has to know when to introduce the new information, how to connect it with the old one, and whether it is 
new to the addressee or not. On the other hand, the listener has to be able to interpret this new information and relate it to the previous one. Many examples of bas can be identified in the data to serve as a topic launcher whereby new information relevant to the given discourse context is introduced. To illustrate, consider example (1).

\section{Example (1)}

M1: Yãxi bigulū bidu iyṣēr influwanza xirfān bilbalad . [Oh dearest! they say, "There will be Qfever in the country.]

M2: wallah ismiYit fi influwanza. [I heard about it.]

M1: Jū ya?ni? [What does that mean?]

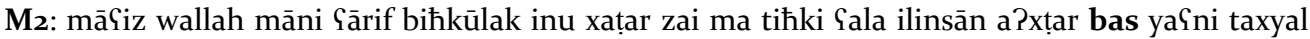
inu yișēr kilo illaћmih iblēra. [Goats! I do not know; they said it is dangerous on humans, dangerous, but imagine the price of one kilo of meat be 1 JD.]

Mı: hāẹ illi bidna iyāh. [This is our wish.]

The participants in example (1) are discussing Q-fever, which mainly infects sheep and goats. M1 claims that he heard that there will be Q-fever outbreak in Jordan, to which M2 replies that he also heard the same thing. M1 seems to have no knowledge about this disease, so he asks M2 "What does that mean?" M2 starts to explain to M1 what this disease means and how contagious and dangerous it is on the health of human beings. Then, M2 initiates a new topic by asking M1 to imagine that the price of meat drops sharply to 1 JD for a Kilo because of the disease. Mi seems happy to hear that and jokingly reply that this is what people want. In this category, bas tend to occur immediately before a new conversational topic to open a new turn of interaction or introduce new information or ideas. In this particular example, bas is used to present newly supposed information (Hee Lee, 2003) that the listener finds himself obligated to answer, which is "Imagine that the price for 1 kilo of beef drops to 1 JD!). Therefore, bas in this regard is used as a topic initiator.

\subsection{Signaling Topic Change}

The conversation process often requires participants to modify and/or change the topic of discussion and the information relevant to it. It follows that both participants should have presuppositions about the information to be introduced. Participants constantly change their methods of conveying information to help one another achieve communicative intention intended by their speech (Zhao, 2014). One of the methods participants use in JSA to signal the change of a discourse topic is by the use of bas at the beginning of an utterance.

Example (2)

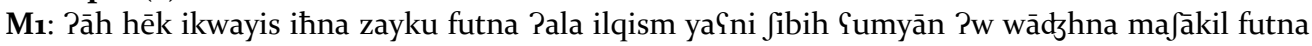

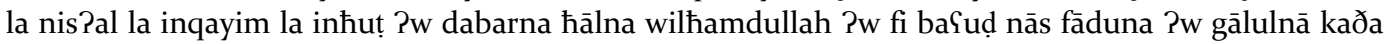
Pw kaða bas Jū șār maSak Pinit binisbih larusūm. [Yeah, right! we have the same experience. When we started studying at the department, we were ignorant, and we encountered problems. We did not ask anyone. Thank God, things went smoothly. Some people helped us but what happened about your tuition?]

In example (2) above, the speaker tells an acquaintance how ignorant they were when his colleagues and he first joined the department and about the challenges they faced back then. He is also tells him how independent they were, and that they did not ask anyone for help. However, some students helped them make it through. Then, the speaker changes the current topic by asking the hearer the following question "What happened with you regarding the tuition?" By using bas in the beginning of the turn, the speaker prepares the hearer for a question he needs an answer for. The new topic seems to have some sort of relevance with the old topic although it seems as a completely new topic of discussion. Thus, bas in this example constitutes a departure from the current topic to a new topic or new information (Fraser, 1999). To a great extent, this function may overlap with the function of "Initiating a topic". 


\subsection{Closing a Turn}

In any normal interaction, there are always two or more participants communicating with one another, where only one person holds the floor at one time. This is called "turn taking", which involves three strategies: taking the floor, holding the floor and yielding the floor (Yule, 1996). Speakers know when to take the floor and when to yield it to let the other participant take the turn. One of the mechanisms used to yield the floor, i.e., close a turn is by the use of certain words and phrases, using body language, or intonation. The data show that in JSA, bas is used as a pragmatic marker to end a turn and yield the floor. Example (3) illustrates this use.

\section{Example (3)}

F1: Saqadti il agid [Have you got married?] all.]

F2: ma șār fỉh nașēb laGinuh ḑ̧iduh itwafa w bas. [Not yet. His grandfather died, and that is

\section{F1: yā allah [Oh! My God]}

F2: allah yuktub lēna illi fih ilxēr [May God choose what is best for us!]

The two female participants in this interaction are discussing the marriage of $F_{2}$, which was supposed to occur at a time prior to their interaction. F2 produces a negative reply and a justification stating that she did not get married because her fiancé's grandfather had died, and that is all she wants to say. In her response, F2 shows her unwillingness to talk about the marriage issue for some reason, so she closes the turn and gives the floor to $\mathrm{F}_{1}$ by using bas at the end of her utterance. F2, then, takes the floor right away and expresses her sorrow and sadness to what happened.

\subsection{Ending a Conversation}

Bringing a conversation to an end involves certain strategies based on the social context, which includes the relationship between the participants, the topic, and the smoothness of conversation, and so on. Sometimes, participants feel that their interaction has to end for different reasons, such as unhappiness about the ongoing interaction, conflicting viewpoints, running out of time, sparing the face of the hearer, etc. The data show that speakers of JSA use bas to end of a conversation.

\section{Example (4)}

Mı: bas bas bas bikafi lahūn... ilhag Gali gāYid Pașlan. [Stop! Stop! Stop! That is enough... It is my fault I am sitting with you.]

M2: yāxi intaḍir ifwai xalēni afahmak lēe intah hēk. [Oh dear! Wait and let me explain to you. Why are you behaving like this?]

$\mathrm{M}_{1}$, in example (4), is furious with $\mathrm{M}_{2}$ and is really unhappy in the ongoing conversation for some reason. M1 bluntly tells $\mathrm{M}_{2}$ that he is no longer interested in the conversation, and he even blames himself for sitting with him. It should be noted that the speaker used bas three times consecutively at the beginning of his turn, followed by the expression "That is enough". This use shows how mad the speaker is and how serious he is about ending the conversation and leaving. The hearer, on the other hand, tries to calm him down and get him to wait until he clears things up. He also wonders why the speaker is behaving this way. Thus, the speaker here employs bas to convey that the conversation is over. Noteworthy is the fact that speakers often use body language, such as hand movements and facial expressions to wrap things up in a conversation.

\subsection{Mitigating Face Threatening Acts}

A face threatening act (FTA) is an act that challenges the face wants of an interlocutor (Brown \& Levinson, 1987). On the other hand, mitigating face threats is a politeness strategy used by speakers to preserve the listeners' social image and to make them feel appreciated and respected (Brown \& Levinson, 1987). Mitigating markers "signal the speaker's desire to reduce the face loss associated with the basic message" (Fraser, 1990, p. 383). The data show that in order to mitigate a FTA (e.g., 
softening a negative response, showing disagreement, etc.), speakers of JSA use bas as a mitigating device to help them achieve that. In this function, bas is noted to be used in utterance-initial position. Consider example (5).

Example (5)

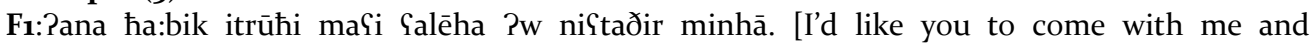
apologize to her.]

F2: Yã rēt... bas ma bagdar. [I wish, but I could not.[

The speaker $F_{1}$ is politely asking an acquaintance $F_{2}$ to go with her and apologize to someone. The hearer F2 turns down the offer, also, politely by firstly saying (I wish; I could), then she continues her act of refusal by using the DM bas followed by the utterance (I could not), which, if used alone, would constitute an FTA. However, beginning the utterance with bas mitigates the act of refusal. In this example, bas is used as a pragmatic marker that connects speech to mitigate the refusal response. Hence, bas is a strategy used to mitigate an FTA.

\subsection{Indicating Speaker's Hesitancy}

In natural conversations, speakers sometimes find themselves hesitant to produce an utterance for different reasons, one of which is caring about hearers' feelings. The data reveal that bas can be used to indicate speaker's hesitancy. That is, it can be used as a hedging device to express uncertainty (Aijmer, 2002). Bas occurred in the data with expressions that show uncertainty, such astrubama, بظن badin and مكن mumkin. Consider example (5) below.

\section{Example (6)}

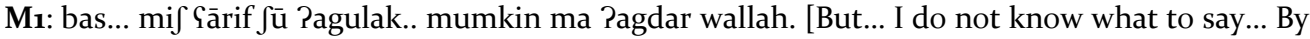
God, I may not be able to do that.]

M2: Allah yidzēb illi fih ilxēr. [May God choose the best for us!]

The speaker M1 in this example is hesitant to say something that may threaten the face of the hearer, by embarrassing him or making him feel mad. He is trying to tell the hearer M2 that he may not be able to do what he asked for. At the same time, M1 is trying to let M2 know that he is unhappy about not being able to help. By using bas, $\mathrm{M}_{1}$ is showing $\mathrm{M}_{2}$ that he is hesitant to say what he intends to say because he is willing to help, but he may be unable to do so. The use of bas in this example also enables $\mathrm{M} 2$ to perceive the speaker's hesitancy and provides him a chance to withdraw or switch the current topic. The hearer's response shows that he completely understands the speaker's inability to help and that he leaves it in the hand of God.

It is important to note that, the use of bas as a hesitancy marker is often accompanied with nonverbal cues, such as body language, pauses, tone of voice, and prolonging the /a/ vowel or (geminating) stressing the /s/ sound in the word bas, especially if you are about to share a very personal piece of information. Using bas to indicate hesitation about a certain utterance partially overlap with its use in mitigating FTAs and introducing new information. In other words, the speaker's hesitancy in potentially causing hard feelings in the listener motivates him/her to use such a DM.

\subsection{Making a Correction}

It is indicated in the data that bas is used as a correction particle in JSA to correct a preceding utterance in discourse. Speakers in this category usually initiate an assumption, and then they correct it directly after bas if they feel obligated to. This use is very common in JSA.

\section{Example (7)}

M1: bas mi $\int$ ikwayis itkūn innihāyih hēk.[But, it does not have to end this way.]

M2: hāi kulha taxyulāt bas inhā Gilmiyih bas kulfi ya@ni ib̧lm Allah ma miņrfif ?iji Jāyif. [All of these are imaginations, also they are scientific facts and Allah is omniscient. We do not know anything, you know.] 
M2 in example (7) expresses his concerns and dissatisfaction about a particular topic he is discussing with $\mathrm{M}_{2}$, who tries to explain to $\mathrm{M}_{1}$ that the issues under discussion are mere imaginations. However, in his second proposition, M2 makes a self-correction by saying that these imaginations can also be scientific facts. The use of bas before the utterance indicates that the speaker realizes that he made a mistake of some sort and he wants to correct it. M2 also uses another bas in the following utterance with the same function; he is still trying to repair the error that occurred in the first utterance. In his response, it is evident that M2 uses the DM bas as a correction or repair device.

\subsection{Attracting Hearer's Attention}

An important aspect of conversation is that the speaker usually tries his best to attract the hearer's attention, especially if $\mathrm{s} / \mathrm{he}$ is about to say something important. In fact, the beginning of a conversation is always important whereby the speaker tries to make the hearer acknowledge him/her by drawing his/her attention, and thus, increases the chances of successfully passing the message through. There are a number of strategies used to grab the attention of the hearer. The data of this study show that bas has a pragmatic role of attracting the attention of the hearer. Consider the following example:

Example (8)

F1: bas... $\int \bar{u}$ ra?yik bi halfikrah? [But ... what is your opinion about this idea?]

F2: mi $\int$ galaṭ wallah xalēna indzarib winfüf ma ibnixsar $\int \mathrm{i}$. [By God, it is not a bad idea... let's try it and see the consequences. We will not lose anything.]

From example (8) above, it can be observed that Mi attempts to elicit the hearer's involvement in the conversation by employing bas as an attention grabber. By the use of bas, the hearer's attention is attracted to the speaker's question, which is about to be asked "What do you think about this idea?" In this category, bas was noted to be followed by a pause or by prolonging the vowel /a/ bās, which may be used to help enhance the impact of the attention grabber. Therefore, bas in example (8) can be considered an attention grabber used to get the attention of the hearer to the new topic being introduced.

\subsection{Expressing Restriction and Condition}

The data reveal that bas in JSA is used as a restrictive DM, meaning only. It is used as a modifier to restrict and limit the details in an utterance or to impose a condition on the hearer. In example (9), M1 asks M2 if he likes football; M2 provides a negative answer. Then, M1 asks M2 if he watches football matches. M2 answers that he only watches the Jordanian League. In this example, M2 uses bas at the end of his statement to restrict his answer to only one thing, which is the Jordanian League. Like only in English, bas in this category can precede or follow a subject, a verb, or a whole structure.

\section{Example (9)}

M1: ilak Gala ilfațbūl? (Do you like football?)

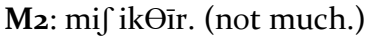

M1:wala bittābiৎ mubārayāt wala ifi? [Do not you even watch football matches?]

M2: iddawri il?urdini bas. (The Jordanian League only.]

One of the interpersonal functions of DMs is to express a reaction to the preceding utterance (Aijmer, 2002). The data show that bas can be used to stipulate a condition or requirement on the speaker for something he previously uttered. In other words, by using bas, the speaker imposes a condition on the hearer, who has to accept it or refuse it. In example (10), M1 asks M2 if he could pick him up in the morning. M2 expresses his willingness to do so. However, he imposes a condition on M1, which is "being ready at a certain exact time". Bas is used at the beginning of the turn, followed by the condition imposed by $\mathrm{M} 2$ as shown in example (10). 


\section{Example (10)}

M1: ibtigdar itmur Galai itwașilni małak ișșubuh. [Can you pick me up in the morning?]

M2: bas ibfarṭ itkūn ḑāhiz issā̧ah 7 bizzabț. [But, under the condition that you be ready exactly at 7.]

\subsection{Expressing Disbelief / a Question}

Bas is used in JSA as a question marker. It comes as a single word utterance or associated with other question words, such as why, when, where, who or longer questions in the form of imperatives. It is often used as a yes-no question marker, the answer to which is either yes or no. However, the answer to a question containing bas is sometimes another bas used as a confirmation marker. In the conversation below, M1 asks M2 in a form of a statement about the truth of what he heard "I heard that you are registering for only 12 credit hours", to which M2 gave a positive reply by stating his intention to do so. Then, M1 in the third turn uses Bas to obtain a direct answer from M2, who confirms his answer by using bas at the beginning of his turn, followed with an explanation by providing a reason for doing so, which is the financial hardships his father is going through.

\section{Example (11)}

M1: ismiGit bidak itsaḑil 12 sāYah? [I heard that you want to register 12 credit hours.]

M2: hēk nāwi Pah. [Yes, I have an intention to do so.]

M1: bas? [Only 12 hours?]

M2: bas ḍurūf ilwālid șafbah ifwai. (Yes, my father's financial situation is somewhat tough.)

Moreover, bas can be used to express wonder, surprise, doubt or disbelief, meaning Is that all? In example (12) M1 tells M2 that he searched the net and found only two articles about a certain subject. In the response turn, M2 expresses his surprise and disbelief about M1's utterance, i.e., he doubts the fact that there are only two articles in the net about the subject. Mi introduces his turn by bas, and then he expresses his doubt about Mz's utterance.

\section{Example (12)}

M1: wallah dawarit bilnit ma lagēt gèer maqālēn. [By God! I searched the internet, and I found only two articles.]

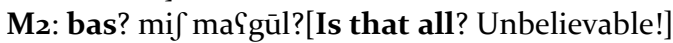

\subsection{Providing Interpretation}

One of the pragmatic functions of bas that surfaced from the data is that it can be used to provide interpretation or justification for a preceding utterance. It can be regarded as an elaborative marker (Fraser, 1999) that adds more information to a previously uttered statement. Therefore, in this function the following utterance constitutes a modification of some kind to the discourse preceding it. In JSA, bas is uttered in utterance-initial position to provide a justification for the preceding proposition. As a way of illustration, let's consider the following example (13).

\section{Example (13)}

M: yāxi iflūn ildaktūr fădi? [Oh dear! How is Dr. Fadi?]

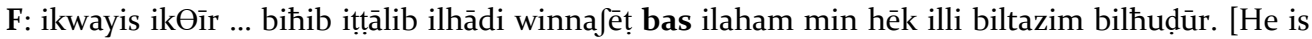
very nice... he likes quiet and diligent students, but above all, those committed to attending class.]

$\mathrm{M}$ is asking $\mathrm{F}$ about a professor called Fadi. Then, $\mathrm{F}$ answers back by providing $\mathrm{M}$ with some information about the professor. F tells $\mathrm{M}$ that Fadi is a very good professor who admires quiet and diligent students, and above all, those who comply with attendance. The proposition who "comply with attendance" was preceded by bas to introduce more important information related to the preceding discourse. 


\subsection{Showing Contrast}

Bas is also used in JSA as a contrastive marker. According to Fraser (1999), contrastive markers signal a relationship between two utterances where the utterance following either contrasts or denies another proposition contained in the preceding discourse. In this category, bas is employed by the speaker to begin a turn that contrasts or denies a previous turn uttered by the other party. It can sometimes be used to indicate politeness, where the hearer tries to disagree with the speaker's utterance in a polite manner. In example (14), both males are talking about a football match between Al- Faisaly and Al Jazeera (both are Jordanian football clubs). M2 begins his speech by praising the performance of one of the teams in a particular match, then he contrasts it after bas with the performance of the other one. In this category, the contrasting statement is always preceded by bas, which is used as a contrastive device.

\section{Example (14)}

M1: kēf kānat li@bit imbāri ћ? [How was yesterday’s football match?]

Mı: ilfēṣali li̧̧bu zai il؟ama bas ilḑ̧azērah kānu lahabih. [Alfaisali played terribly, but Aljazeerah played fascinatingly.]

\subsection{Expressing Regret}

Bas can also be used in JSA to initiate a turn to express regret for something mentioned in a previous discourse. It is found in the data to be followed by words like harām [woe!], lisu: ilhath, unfortunately, and xasārah (Alas!). In Example (15), both $\mathrm{M}_{1}$ and $\mathrm{M}_{2}$ are discussing an English optional course in which the hearer got a low mark. M2 uses bas to indicate his unhappiness about the grade and at the same time his regret for not working hard enough in that course. By the use of bas harām, M2 tries to motivate M1 to work hard in the course and aim for more than $76 \%$.

Example (15)

Mı: Kam nazalthā? [What was your grade in this course?]

M2:76

M1:Pana bidi Panazil zayak min 76-8o [I would like to get the same as yours, from $76-80$.]

M2: bas harām! Pilkūrs sahil. [But what a loss! The course is easy.]

\subsection{Expressing Agreement}

Expressing agreement in FTF interactions protects the addressee's face, preserve the addressee's selfesteem, and strengthen solidarity with the addressee (Brown and Levinson, 1987). In doing so, the speaker uses some words or phrases, such as "I agree with you, exactly, Ok, etc." In JSA, speakers were found to use bas to express agreement and show that they have common grounds with the hearers, followed by the agreement utterance.

\section{Example (16)}

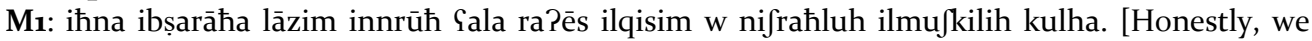
should go to the head of department and explain the whole issue to him.]

M2: bas haða illi kunt bidi iyyāh. Mitafgēn infā̧ Allah. [That's it. This is exactly what I wanted. We have an agreement then God willing.]

$\mathrm{M}_{1}$ and $\mathrm{M}_{2}$ in this examples are discussing an issue they have with the department they study at. M1 states the necessity of approaching the Head of Department to explain that issue to him. M2 states that he completely agrees with what Mı has proposed and even claims that he has the exact same thing in mind. Then, he clearly states his agreement by saying that "We have an agreement". The speaker uses bas in the beginning of the whole turn to express agreement with his partner. Then, he clearly introduces his agreement proposition in what follows. The data show that bas always comes at the beginning of the turn in this category. Body language and intonation play an important role in expressing this function. 


\subsection{Indicating Emphasis}

Bas is also used in the data to serve the pragmatic function of indicating emphasis. All the instances in this particular function reveal that bas always comes at the beginning of the turn, followed by the statement to be emphasized. Consider example (17).

Example (17)

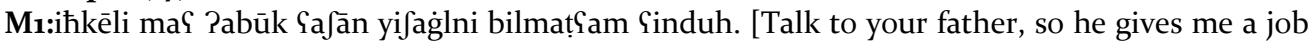
at his restaurant.]

M2: infallah. [God willing!]

Mı:bas billah Salēk la tinsa. [But.. by God do not forget.]

M2: bawi@dak aћkēlak maSuh. [I promise; I will talk to him.]

The speaker, M1, who wants the hearer, M2, to help him find a job at his father's restaurant uses an emphasis strategy with the hearer by using bas at the beginning of the third turn. The employment of bas followed by the utterance "Do not forget", indicates that the speaker wants to put more pressure on $\mathrm{M}_{2}$ to ensure that he provides help although M2 states his readiness to do so in the second turn. Due to Mi's pressure by using bas, M2 in the fourth turn pledges to provide assistance in the matter.

\subsection{Expressing a Filler}

Fillers are words, phrases, and sounds (e.g., like, y'know, I mean, um, uh) that have no meaning and indicate hesitation, pauses, or continuation in speech. Although considered redundant and syntactically detachable, they usually have "pragmatic implications in that they reflect the speaker's intentional effort while executing interactional communication" (Qianbo, 2016, p. 109). They also help display communicative strategies (Fraser, 1990). The data reveal that bas can be used as a filler word in JSA. In example (18), M2 uses two instances of bas in his turn as filler words. In this example, bas here is equivalent to "I mean" in English; it may be used here to indicate uncertainty, hedges, or pause.

\section{Example (18)}

Mı:bēni w bēnak zādūha ifwai w Jū rāh ti@mal? [Between us, they over did it. What will you do?]

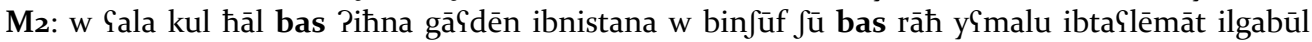
[Anyway, but we will wait and see what they will do in the admission's regulations.]

\section{Conclusion}

This study has investigated the use of bas as a DM in JSA. It concludes that bas serves a number of pragmatic functions in JSA, particularly sixteen functions. These functions are JSA-specific in that only speakers of JSA can produce them and understand them. Studying the actual use of bas in natural conversations in JSA, this study concludes that bas is functional and fulfills a plethora of pragmatic functions. Specifically, bas can be used to initiate a topic, signal topic change, close a turn, end a conversation, indicate speaker's hesitancy, mitigate FTAs, make a correction, attracts hearer's attention, express restrictions and conditions, show disbelief and indicate a question, provide interpretation, show contrast, express regret, show agreement, indicate emphasis, and finally to fill in gaps in an interaction. Bas can occur initially, medially, and finally in an utterance based on the context in which it is used. It is worth mentioning that context is very important in identifying the exact function of bas. This study reveals that bas is not only used as a linguistic device to relate preceding utterances with following discourse, but to build rapport among participants in an interaction. This study suggests that DMs in Arabic play a vital role in people's daily communication, and thus, should not be neglected by scholars. 


\section{References}

Abdeljawad, H., \& Abu Radwan, A. (2016). Conversational coherence: The role of inzeen (Okay) in Arabian Gulf spoken Arabic. International Journal of Arabic linguistics, 2(1), 1-18.

Aijmer, K. (2002). English discourse particles: Evidence from a corpus. Amsterdam: John Benjamins.

Alazzawie, A. (2015). Adi as a discourse marker in spoken Iraqi Arabic. Theory and Practice in Language Studies, 5(7), 1352

Al Harahsheh, A., \& Kanakri, M. (2013). The pragmatic functions and the translatability of "Ťayib" in Jordanian spoken Arabic. US-China Foreign Language, 11, (3), 196-202.

Al Rousan, R. M. (2015). The use of discourse marker "maS nafsak" in Saudi Arabic: A pragmatic perspective. International Journal of Linguistics, 7(3), 33-48.

Blackmore, D. (1992). Understanding utterances. Oxford: Blackwell.

Brinton, L. (1996). Pragmatic markers in English: Grammaticalization and discourse functions. Berlin: Mouton de Gruyter.

Brown, P., \& Levinson, S. (1987). Politeness. Cambridge: Cambridge University Press.

Chen, K. J. (2002). The analysis of pragmatic functions of tag questions in English and Chinese conversation. Modern Foreign Languages, (3), 8-14.

Fraser, B. (1990). An approach to discourse markers. Journal of Pragmatics, 14, 383-395.

Fraser, B. (1996). Pragmatic markers. Pragmatics 6 (2), 167-19o.

Fraser, B. (1999). What are discourse markers? Journal of pragmatics, 31(7), 931-952.

Fraser, B. (2006). Towards a theory of discourse markers. In Approaches to Discourse Particles, Kerstin Fischer (ed.), 189-204. Amsterdam: Elsevier.

Fraser, B. (2009). Topic orientation markers. Journal of Pragmatics 41, 892-898.

Hee Lee, C. (2003). The Use of the discourse marker say in conversational English. SNU Working Papers in English Language and Linguistics, 2, 133-156.

Kanakri, M., \& Al-Harahsheh, A. (2013). The discourse analysis and pragmatics of ?a:di in Jordanian spoken Arabic. International Journal of English Linguistics, 3 (6), 59.

Labov, W., \& Fanshel, D. (1977). Therapeutic discourse: Psychotherapy as conversation. Orlando, FL: Academic Press.

Lenk, U. (1998). Discourse markers and global coherence in conversation. Journal of Pragmatics, 30 (2), 245-257.

Levinson, S. (1983) Pragmatics. Cambridge: Cambridge University Press.

Louwerse, M. \& Mitchelle, H. (2003). Toward a taxonomy of a set of discourse markers in dialog: A theoretical and computational linguistic account. Journal of Discourse Processes, 35 (3), 199-239.

Müller, S. (2005). Discourse markers in native and non-native English discourse. Amsterdam: John Benjamins.

Qianbo, L. (2016). A Case study on the pragmatic use of discourse markers. Canadian Social Science, 12 (11), 106-113.

Redeker, G. (1991). Linguistic markers of discourse structure. Linguistics 29 (6), 1139-1172.

Schiffrin, D. (1987). Discourse markers. Cambridge: Cambridge University Press.

Schourup, L. (1999). Discourse markers. Lingua, 107. 227-265.

Wang, Y., (2011). A Discourse-pragmatic functional study of the discourse markers Japanese ano and Chinese nage. Intercultural Communication Studies 20, 42-61.

Zhao, H., (2014). The textual function of discourse markers under the framework of relevance theory. Theory and Practice in Language Studies, 4, (10), 2105-2113. 